\title{
Salt handling and hypertension
}

Kevin M. O'Shaughnessy ${ }^{1}$ and Fiona E. Karet',3

${ }^{1}$ Clinical Pharmacology Unit, ${ }^{2}$ Division of Renal Medicine, and ${ }^{3}$ Department of Medical Genetics, University of Cambridge, Cambridge, United Kingdom.

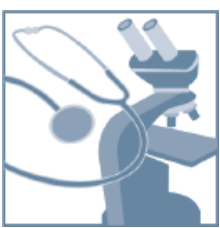

The kidney plays a central role in our ability to maintain appropriate sodium balance, which is critical to determination of blood pressure. In this review we outline current knowledge of renal salt handling at the molecular level, and, given that Westernized societies consume more salt than is required for normal physiology, we examine evidence that the lowering of salt intake can combat hypertension.

\section{Introduction}

Salt was once ascribed magical properties, and its spillage carried ill omen. It has been used as a monetary device throughout human history, and its economic influence has started wars. It should thus come as no surprise that salt consumption is still a controversial topic, especially among medical epidemiologists, health policy makers, and lobbyists for the salt industry $(1,2)$. An omnivorous diet that includes commercially prepared meals provides several times the amount of sodium needed for normal physiologic function, and debate as to the importance of diminishing this consumption in the general population remains vociferous.

In evolutionary terms, our exposure to a high-salt intake (>6 $\mathrm{g} / \mathrm{d}$ ) is recent. This probably explains features in modern humans such as the very low sodium content of human breast milk (about $10 \mathrm{mM}$ ) compared with that of nonprimate mammals. Our hominid ancestors genetically adapted over hundreds of millennia to a very low-salt environment in equatorial savanna, probably consuming less than $0.1 \mathrm{~g} / \mathrm{d}$. Preliterate humans show no age-related blood pressure changes until they move into an urbanized high-salt environment.

The observation that salt intake is associated with hypertension is not new: the "hard pulse" resulting from a high salt intake is referred to in the Nei Ching, a classic Chinese text probably dating from the first millennium BCE (3). Over the past half-century or so, much energy has been devoted to dissecting this relationship. Work at Duke University in the late 1940s first showed the effectiveness of a very low-salt diet (based on rice and giving an intake less than $0.5 \mathrm{~g} / \mathrm{d}$ ) in reducing blood pressure (BP) in patients with malignant hypertension, a sometimes irreversible condition where uncontrolled severe elevation of BP results in end-organ damage to kidneys, heart, brain, and eyes.

The kidney's contribution to sodium homeostasis is crucial (Figure 1). Prior to the elucidation of the molecular contributors to both renal sodium reabsorption and the linked functions of potassium and chloride handling, it was evident that the kidney was centrally

Nonstandard abbreviations used: chloride channel, kidney B (CLC-KB); Dietary Approaches to Stop Hypertension (DASH); epithelial sodium channel (ENaC); mineralocorticoid receptor (MR); pseudohypoaldosteronism type 1 (PHA1); reninangiotensin-aldosterone axis (RAAA); sodium chloride cotransporter (NCCT); sodium-potassium-chloride cotransporter (NKCC2); with no lysine (WNK).

Conflict of interest: The authors have declared that no conflict of interest exists. Citation for this article: J. Clin. Invest. 113:1075-1081 (2004). doi:10.1172/JCI200421560.

The Science in Medicine series is supported in part by a generous grant from the Doris Duke Charitable Foundation. involved in BP determination. For example, it was demonstrated in the 1970s that transplantation of kidneys from genetically normotensive rats into genetically hypertensive recipient strains could prevent or correct hypertension (4). Furthermore, Guyton's pressure natriuresis theory, which remains a cornerstone of our thinking concerning sodium homeostasis, argues that hypertension cannot be sustained without active renal involvement $(5,6)$.

\section{Human genetics}

Attempts to identify the genes whose function or, indeed, dysfunction affects human BP have shed light on the molecular pathways involved (7). It is generally accepted that in any individual, some five or six genes contribute to the final arterial pressure level, which reflects a complex network of gene-gene and geneenvironment interactions. In some individuals, however, defects in a single gene cause marked abnormalities of BP. The genetic causes of almost all of these rare Mendelian forms of hypertension and hypotension have now been elucidated, and, remarkably, they converge upon a final common pathway: the regulation of sodium reabsorption in the kidney (Figure 1). Mutations that increase renal sodium reabsorption increase BP, whereas those that decrease renal sodium reabsorption serve to decrease it. This analysis has had a major impact on our understanding of renal homeostatic mechanisms and underscores the importance of salt handling in determination of BP.

\section{Liddle syndrome}

Grant Liddle described a three-generation kindred with autosomal dominant inheritance of early-onset hypertension and hypokalemic alkalosis associated with suppressed levels of aldosterone (8). The index patient received a cadaveric renal transplant in 1989, after which her hypertension and biochemical derangements resolved (9). The abnormalities in Liddle syndrome can be ameliorated by a low-salt diet plus amiloride or triamterene, which are antagonists of the epithelial sodium channel $(\mathrm{ENaC})$ of the collecting duct.

Liddle syndrome is associated with mutations in either the $\beta$ or the $\gamma$ subunit of the non-voltage-gated $\mathrm{ENaC}$ gene $(10,11)$. Mostly, these mutations result in truncations of the cytoplasmic C-terminal tail of the relevant subunit. Consistent with the dominant inheritance pattern, they are associated with a gain of function in $\mathrm{ENaC}$.

In the kidney, functional $\mathrm{ENaC}$ channels are expressed at the apical surface of collecting duct principal cells and are composed of at least three subunits: $\alpha, \beta$, and $\gamma$. ENaC activity is chiefly regulated by variation in the number of channels present at the cell surface. Normally, removal of $\mathrm{ENaC}$ occurs following an inter- 


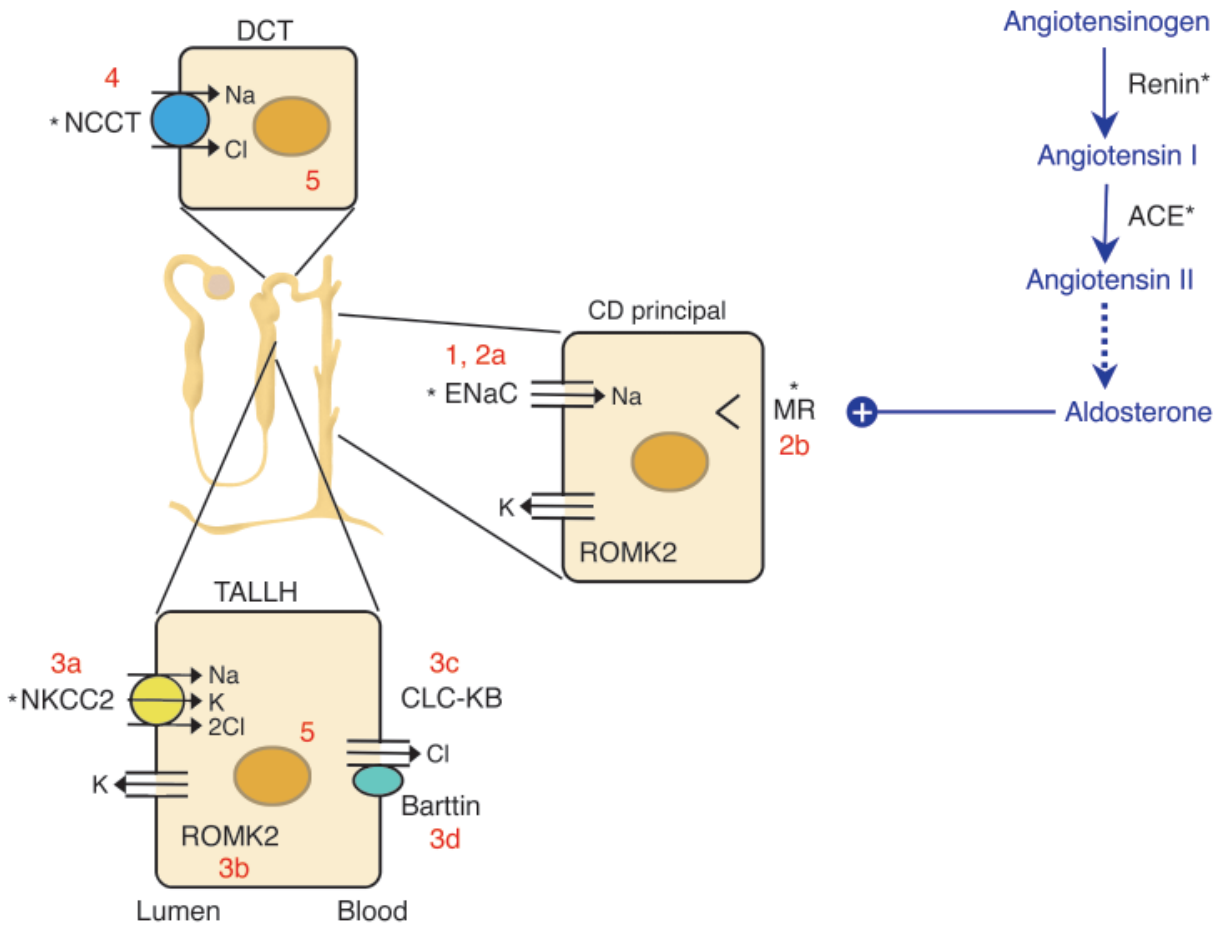

\section{Figure 1}

The renin-angiotensin-aldosterone axis and molecular pathways of sodium reabsorption in the nephron. A cartoon of a nephron is shown, with sodium-reabsorbing cells of the thick ascending limb of the loop of Henle (TALLH), distal convoluted tubule (DCT), and collecting duct (CD). The latter is responsible for fine regulation via the aldosterone-activated mineralocorticoid receptor (MR). In all cells, sodium exits the basolateral compartment via the $\mathrm{Na} / \mathrm{K}$-ATPase (not shown). Aldosterone synthesis is controlled by angiotensin II. Numbers reflect cellular components affected in disorders of sodium homeostasis referred to in the text: 1, Liddle syndrome; 2a/b, recessive/dominant PHA1; 3a/b/c/d, types I/II/III/IV Bartter syndrome; 4 , Gitelman syndrome; 5, Gordon syndrome. * Sites of action of antihypertensive drugs. ROMK2, renal outer medullary potassium channel.

action between a conserved PY motif in the C-terminal tail of one of its subunits and the E3 ligase Nedd4-2 $(13,14)$, resulting in ubiquitination, internalization, and proteasome-mediated degradation. Nedd4-2 is phosphorylated by the action of serum and glucocorticoid kinase 1 , the function of which is upregulated by aldosterone $(15,16)$. Once Nedd $4-2$ is phosphorylated, it loses the ability to interact with $\mathrm{ENaC}$, leading to the observed increase in activity in response to this hormone. Liddle syndrome mutations all affect the PY motif, leading to constitutive ENaC expression and, therefore, increased sodium reabsorption. Thus, the kidneys of patients with Liddle syndrome behave as if they were consuming and retaining excessive amounts of salt, and a low-salt diet is an important feature of therapy.

\section{Pseudohypoaldosteronism type 1}

Pseudohypoaldosteronism type 1 (PHA1) represents the clinical inverse of Liddle syndrome. It is a rare inherited disorder characterized by renal salt wasting and hyperkalemic metabolic acidosis, despite markedly elevated renin and aldosterone levels, in the setting of otherwise normal renal and adrenal function (17). The clinical picture is thus one of renal resistance to mineralocorticoids. Clinically distinct autosomal recessive and autosomal dominant forms of the disease have been described. Both generally present in the first weeks of life, with dehydration, sodium wasting, hyponatremia, and hyperkalemic metabolic acidosis. In recessive PHA1, patients have severe sodium wasting from the colon, the sweat and salivary glands, and the kidney. These children have recurrent life-threatening episodes of salt wasting and hyperkalemia, requiring lifelong sodium supplementation and treatment with potassium-binding resins.

Recessive PHA1 is caused by homozygous loss-of-function mutations in any one of the ENaC subunits $(18,19)$, causing a marked reduction of sodium reabsorption in the cortical collecting duct. The linked secretions of potassium and hydrogen ions in this segment are blocked as well. The ensuing hyperkalemic volumedepleted state stimulates the renin-angiotensin system, resulting in elevated aldosterone levels and maximal activation of the mineralocorticoid receptor (MR). Because of the absence of ENaC, the $\mathrm{MR}$ is unable to stimulate sodium reabsorption, and so sodium wasting and hyperkalemic acidosis persist.

The severity of the clinical course of recessive PHA1 highlights the crucial role of $\mathrm{ENaC}$ in sodium homeostasis, even in individuals ingesting a high-salt diet. There is some variability in the prognosis of patients with recessive PHA1. For patients with homozygous null mutations, the outcome is often very poor. Even minor illness can bring on rapid deterioration with hypotension and hyperkalemia; nausea and vomiting often herald and then accelerate the clinical decline.

In the dominant form of PHA1, sodium wasting is limited to the kidney. While these patients may be quite ill at birth, they typically have a much milder course, generally responding well to salt supplementation. They may even be able to discontinue treatment after the first few years of life. Heterozygous loss-of-function mutations in the MR gene cause this form of the disease (20). 


\section{Inherited metabolic alkaloses: Bartter and Gitelman syndromes}

Bartter and Gitelman syndromes were originally described as variations of a single disease process $(21,22)$ resulting in hypokalemic metabolic alkalosis. More recent biochemical and latterly genetic studies have permitted their separation into distinct disorders, with separable phenotypic characteristics. The genetic defects involve either the salt transporters that are targets of diuretics, or other transporters that are their essential cellular partners. In both diseases, the mode of inheritance is autosomal recessive. To date, four genes have been implicated in the pathogenesis of Bartter syndrome in different kindreds, whereas all cases of Gitelman syndrome studied, now numbering several hundred, are accounted for by mutations in a single gene. In all these variants, the net effect is renal salt wasting, leading to low BP, reduced serum potassium, and an activated renin-angiotensin system.

Features that differentiate Bartter and Gitelman syndromes involve renal calcium handling and deposition, serum magnesium, and clinical presentation (23). In Bartter syndrome, affected individuals may present in infancy or early childhood with severe volume depletion and failure to thrive. Prematurity and maternal polyhydramnios are common. The metabolic dysfunction is usually accompanied by hypercalciuria with normocalcemia and normomagnesemia. Renal tract calcification is very common and may be present even in neonates. Nephrocalcinosis in infancy suggests type I or II Bartter syndrome. Hyperprostaglandinuria and a therapeutic response to indomethacin are features of type II disease. By contrast, those with type III Bartter syndrome may well be normocalciuric and mildly hypomagnesemic, and devoid of renal calcium deposition. Type IV patients are deaf.

The biochemical picture in untreated Bartter syndrome is reminiscent of that occasionally seen in otherwise normal people on long-term loop diuretic therapy. The target for loop diuretics is the electroneutral sodium-potassium-chloride cotransporter (NKCC2), which is expressed apically in the thick ascending limb of Henle's loop (Figure 1). Defects in the gene encoding NKCC2 cause type I Bartter syndrome (24). Subsequently, two further defective genes that result in loss of NKCC2 function have been identified in different kindreds. These are ROMK2, which encodes the inward-rectifier renal outer medullary potassium channel that regulates NKCC2's activity by recycling $\mathrm{K}^{+}$ions back into the tubular fluid (type II Bartter syndrome) (25), and CLCNKB, which encodes the basolateral chloride channel in the same loop of Henle cells (type III) (26). Most recently, type IV Bartter syndrome has been attributed to loss of function in a novel protein, Barttin, an essential cofactor for chloride channel, kidney B (CLC-KB) function in both the kidney and the inner ear, which explains the concomitant deafness $(27,28)$.

By far the majority of patients suspected of having Bartter syndrome in fact have the much more common Gitelman syndrome. The phenotype here is often much milder, usually being identified in late childhood or even in adulthood. Some affected individuals are asymptomatic, but others may be more severely affected, with growth problems and, not uncommonly, joint problems, tetany, and/or other neuromuscular abnormalities. A survey of presenting symptoms (29) highlights the differences in perception between patients and their physicians: while the latter often consider Gitelman syndrome to be asymptomatic, most patients would disagree. Anecdotally, it is reported that affected individuals may note a long-standing preference for salty over sweet foods and snacks. Bio- chemically, Gitelman syndrome is characterized by hypocalciuria and hypomagnesemia with renal magnesium wasting.

Gitelman syndrome patients display many of the biochemical changes seen in individuals on thiazide diuretics, which are commonly used for the treatment of hypertension; indeed, the surreptitious abuse of diuretics (or laxatives) remains the commonest differential diagnosis. All cases of Gitelman syndrome are due to loss of function of the sodium chloride cotransporter (NCCT), the target of thiazides that is present on the apical epithelial surface of distal renal convoluted tubule cells (30) (Figure 1).

The treatment of Bartter and Gitelman syndromes can be difficult, as the degree of salt wasting may be severe. Aggressive replacement of salt, and $\mathrm{K}^{+}$in particular, is essential. Some patients respond well to the administration of indomethacin, especially in type II Bartter syndrome. $\mathrm{Mg}^{2+}$ supplementation is also a useful adjunct in Gitelman syndrome.

\section{Gordon syndrome}

The clinical inverse of Gitelman syndrome is that bearing Richard Gordon's name (31). Here, the hypertension is associated with chloride-dependent sodium retention, accompanied by elevated serum potassium and acidosis. Despite the clinical indication of overactivity of NCCT, linkage to this gene was formally excluded in favor of at least three other loci $(32,33)$. Two responsible genes have now been identified, encoding the with no lysine $(\underline{K})$ kinases WNK1 and WNK4 (34). WNK1 is expressed ubiquitously and is particularly associated with chloride-transporting epithelia at all sites (35), whereas WNK4 expression is limited to the distal nephron. Of particular interest here is recent evidence that WNK4 acts as a negative regulator of NCCT function $(36,37)$. Disease-causing mutations relieve this inhibition, leading to transporter overactivity. WNK4 also affects the renal outer medullary potassium (ROMK) channel (38) and might represent an intriguing novel antihypertensive target.

\section{From molecular genetics to the population}

Clearly, the majority of hypertensive individuals do not have such draconian genetic defects as are outlined above. The singlegene disorders may be rare, but they do highlight an important relationship between salt (of which, in general, we consume vast amounts in excess of our physiologic needs), the reninangiotensin-aldosterone axis (RAAA), and BP. With the aim of extending the important physiologic insights provided by these disorders, as many as several hundred population- or cohortbased genetic studies have been designed to identify genes implicated in faulty BP regulation (see refs. 39, 40). These studies are of two main types: firstly, association studies, usually comparing polymorphisms (or occasionally haplotypes) in or near particular candidate genes; and secondly, genome-wide linkage analyses seeking disease-causing genetic loci. However, despite enormous efforts to find genes in the wider hypertensive population, the results have often been rather mixed. Two genes do stand out for which the majority of data are positive: AGT, encoding angiotensinogen, and the gene encoding the $\beta$ subunit of $\mathrm{ENaC}$ (reviewed in ref. 41). For both of these, there are proven functional consequences to the genetic findings that suggest a subtle alteration in sodium handling in affected individuals. These results from human genetic and physiologic investigations are lent further credence by supporting information from animal models (see below). 


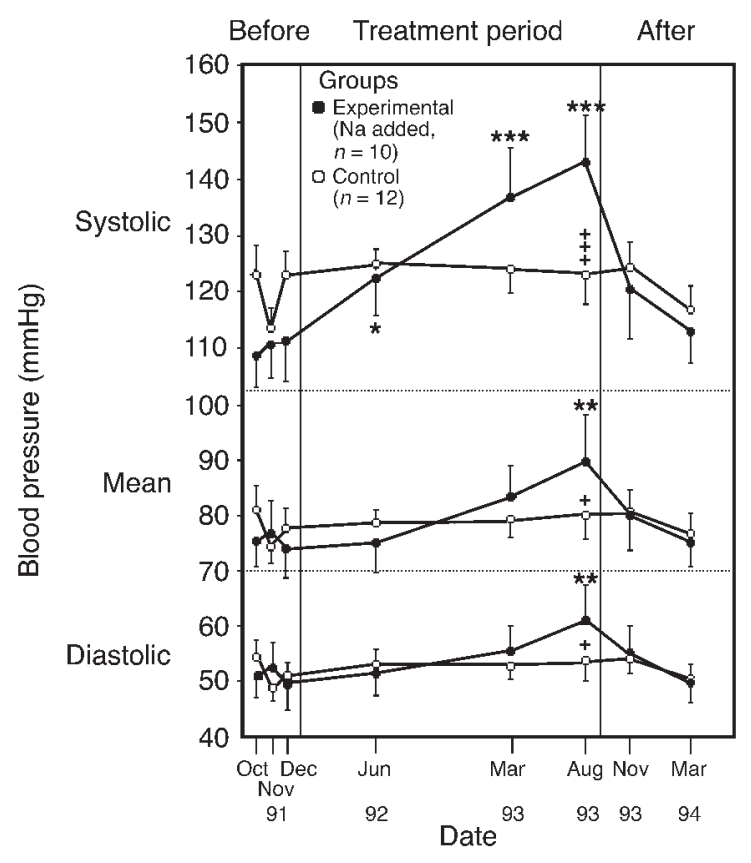

Figure 2

BP changes in chimpanzees fed a salt-supplemented diet. Twenty-two chimpanzees were fed infant formula either alone $(n=12)$ or with added salt $(n=10)$ as follows: $5 \mathrm{~g} / \mathrm{d}$ for 19 weeks, $10 \mathrm{~g} / \mathrm{d}$ for 3 weeks, and 15 $\mathrm{g} / \mathrm{d}$ for 67 weeks. A 20 -week period without added dietary salt concluded the experiment. The BP changes were significantly increased over base line $\left({ }^{\star} P<0.05\right.$, $\left.{ }^{\star \star} P<0.01,{ }^{\star \star \star} P<0.001\right)$ and significantly different between groups $\left({ }^{+} P<0.05 ;{ }^{+++} P<0.001\right)$. Reproduced with permission from Nature Medicine (48).

Many reasons for the lack of major progress from many other association-based and genome-wide approaches can be and have been offered, often based either on criticisms of statistical methodology or power, or on the subset of individuals selected for study. For example, a recent meta-analysis of genome-wide scans included wildly different populations whose difference could easily confound rather than enhance results (42).

\section{Animal data}

Given the enormous background genetic variability of the human species, laboratory animals have been an obvious choice to test hypotheses concerning the relationship between salt and BP, at both the genetic and the dietary level. Recently, targeted manipulation of candidate genes in the RAAA in rodents has added to the armamentarium of evidence. For example, mice over- or underexpressing Agt $(43,44)$ or bearing a Liddle syndrome mutation (45, 46) have proven to be useful and tractable models.

At the whole-animal level, studies of salt consumption are also of interest; indeed, Dahl himself developed the now classical Dahl strain of salt-sensitive rat for the purpose (47). Critics of this particular model, however, point to the levels of salt intake required to increase $\mathrm{BP}$ as being vastly in excess of the human dietetic range; the Dahl rat is typically given $8 \%$ saline to drink. Nevertheless, a careful study in chimpanzees showed that their BP could be raised incrementally by elevation of salt intake from a base line of just $0.5 \mathrm{~g} / \mathrm{d}$ to 5,10 , and 15 $\mathrm{g} / \mathrm{d}$ (Figure 2) (48). As we share $98.4 \%$ of our genome with the chimpanzee, this can be viewed as a robust and relevant model.

\section{Human data}

The modern literature concerning the relationship between salt and BP in humans really begins in the 1960s with the work of Lewis Dahl. He correlated the prevalence of hypertension in five geographically distinct populations with their average daily salt intakes and proposed that BP rises linearly with salt consumption (49).

Many population studies have followed Dahl's, but the results have often been conflicting. For example, the 1988 National Heart, Lung, and Blood Institute-sponsored Intersalt study, the largest of its kind, was drawn from 52 centers in 32 countries and included more than 10,000 individuals (50). Despite its apparent breadth of recruitment, it failed to find any correlation unless four apparent outliers with very low salt intakes were included. Without their inclusion, the range of salt intakes across the centers telescoped from $0.12-14 \mathrm{~g} / \mathrm{d}$ to just $6-14 \mathrm{~g} / \mathrm{d}$. With hindsight, the goal of demonstrating a significant dose-response relationship within this narrow range was probably unrealistic. However, this study did report that in populations with a high salt intake, the relationship between BP and age was stronger than in populations with a low salt intake: between the ages of 25 and 55 the slope was approximately $0.9 \mathrm{mmHg}$ higher for each 10 $\mathrm{mmol}(0.6 \mathrm{~g})$ difference in salt intake.

A problem with inter-population studies is their openness to ecological confounders: the salt content of the diet is not the only difference between so-called low- and high-salt populations (see the discussion, below, of the impact of diet in the Dietary Approaches to Stop Hypertension trial). Like spot BP measurements, single measurements of 24-hour sodium excretion are notoriously variable. This renders studies like Intersalt susceptible to the statistical effect of dilutional regression bias that may reduce (or inflate) any real association of salt intake and hypertension. Indeed, the final credibility of the Intersalt study was heavily undermined by attempts to "correct" for this effect to produce much larger estimates of the pressor effect of salt (51).

An alternative to population-based trials is intervention trials. Dozens of these have been published, though they are often small and have been combined by meta-analysis. The difficulty with this approach is that many trials have flawed design: they often are unblinded or include treated hypertensives. Nevertheless, the metaanalysis by Law et al., focusing on studies that lasted more than 5 weeks, reported an average fall in systolic BP of $5 \mathrm{mmHg}$ resulting from a $50-\mathrm{mmol}(\sim 3 \mathrm{~g} / \mathrm{d})$ reduction in salt intake (52). This is very close to the figures published in a more recent meta-analysis that again focused on the longer-term intervention trials (53).

The single most important intervention trial to date has been the Dietary Approaches to Stop Hypertension (DASH) study, or, more correctly, its sub-study, DASH-Sodium (54). In this study, 412 individuals were assigned to either a normal "American" diet or the DASH diet (high in fruit and vegetables and low-fat dairy products) and one of three different levels of salt intake: high, intermediate, and low, approximating 9, 6, and $3 \mathrm{~g} / \mathrm{d}$ of salt, respectively. Participants were kept on these diets for 30 days, and the BP reductions were as shown in Figure 3. BP reduction was again in keeping with the values from the meta-analyses above, but the effect of the DASH diet was at least as great. This effect of diet can be explained partly by the well-established interplay of dietary cations. For example, intake of calcium dictated by water "hardness" is inversely related to cardiovascular mortality, and calciuresis is a feature of salt loading $(55,56)$. Potassium supplementation similarly lowers BP (57) and may 

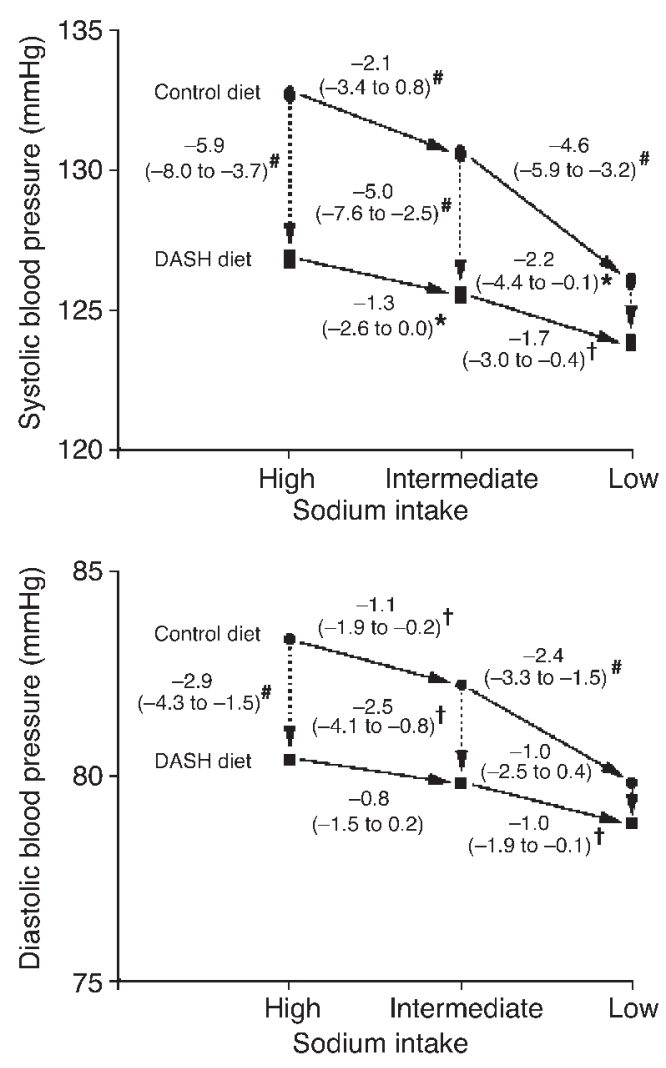

Figure 3

$\mathrm{BP}$ changes during the DASH-Sodium trial. Although arrows are unidirectional, the order in which individuals were assigned a given salt level was random with a crossover design. The numbers next to the lines connecting the data points are the mean changes in BP. The $95 \%$ confidence intervals are given in parentheses. ${ }^{\star} P<0.05,{ }^{\dagger} P<0.01$, and ${ }^{\sharp} P<0.001$; symbols indicate significant differences in $\mathrm{BP}$ between groups or between dietary sodium categories. Reproduced with permission from the New England Journal of Medicine (54).

even protect against stroke independently of its effect on BP (58). Different levels of dietary folic acid and antioxidant vitamins (C and $\mathrm{E}$ ) are also relevant, since they may affect BP through effects on endothelial function and bioavailable nitric oxide levels within the vasculature $(59,60)$. It is thus becoming clear that the dietary context in which salt restriction occurs can be as crucial as the restriction itself.

It is therefore interesting that in recent weeks, the US Institute of Medicine has issued a strong across-the-board recommendation that salt consumption be approximately halved - which may be difficult in these fast-food days - and also advised a significant increase in potassium intake "to lower blood pressure [and] blunt the effects of salt," among other benefits (61).

\section{Salt sensitivity}

The differences between the population and intervention studies on salt intake can be partly explained by interindividual variation in susceptibility to the pressor effect of salt loading. This heterogeneity in response to salt was obvious in the original human intervention studies (62), and in the recent salt loading study in chimpanzees, discussed above (48). Salt sensitivity is affected by age, race, and disease state and hence is more common in the elderly, in those of Afro-Caribbean races, and in type 2 diabetics. There is a definable genetic influence within families (63). However, there is no universal definition of salt sensitivity, and therefore studies resort to arbitrary cutoffs to define salt "responders" and "nonresponders." This has not perturbed the intense trawls for susceptibility genotypes even within the well-characterized DASH cohort itself (64). Until simple molecular markers like these become available, it will be impossible to identify easily those individuals in the general population who would benefit most from dietary salt restriction.

That said, salt restriction is worthwhile in subjects taking specific antihypertensive agents. For example, dietary manipulation in patients receiving amiloride or triamterene should be beneficial, because these act competitively with sodium for transport via $\mathrm{ENaC}$. In addition, there is evidence that reducing salt intake increases the efficacy of angiotensin-converting enzyme inhibitors, because of the RAAA activation that salt depletion induces (65).

\section{Is the anion important?}

Berghoff and Geraci first reported in 1929 that loading hypertensive individuals with sodium bicarbonate did not have the same pressor effect as loading with sodium chloride (66). This observation has been confirmed in more recent studies using citrate or phosphate as the counter-anion $(67,68)$. Loading with equimolar amounts of sodium salts causes similar degrees of $\mathrm{Na}^{+}$retention, weight gain, and suppression of renin and aldosterone, but, curiously, only sodium chloride causes an expansion of the plasma volume and a rise in BP. Why chloride should have this unique property against other sodium salts is not clear, but from a dietary viewpoint it makes little difference, since the bulk of the sodium we consume is in the form of sodium chloride.

\section{Are there critical periods for salt exposure?}

The Barker hypothesis that birth weight and adult $\mathrm{BP}$ are reciprocally related has had a considerable impact on how we now view exposure to factors in utero or in early postnatal life, especially the long-term effects on gene expression that may result (69). Rat models of salt-sensitive hypertension clearly show discrete periods of sensitivity to salt loading that program long-term changes in BP and cardiovascular morphology (70). Evidence that a similar phenomenon can occur in humans is lacking thus far (71) apart from the notable feature of PHA1 whereby neonatal salt repletion usually becomes unnecessary as the child grows. It is conceivable that our scrutiny of salt intake in adults is misplaced, and that we should instead be addressing salt intake in infancy and/or early childhood for maximal benefit.

\section{Conclusions}

Overall, it seems clear that the body's handling of salt has an important effect on cardiovascular status, and recent evidence strongly supports the use of saluretics, in the shape of thiazide diuretics, as first-line therapy for hypertension and coronary heart disease prevention (72). The real contention that exists is not whether salt affects BP, but whether the current body of evidence supports a reduction in salt intake in the general population. Impressive as the DASH data are, for example, this was a short-term study, and dietary manipulations have poor compliance rates in the long term (73). In other areas of therapeutic intervention, the gold standard of proof is a randomized controlled trial showing an impact on disease outcome. Given the prevalence of hypertension and the strong relationship between 
stroke risk and BP, an endpoint of stroke prevention represents an important goal. Antihypertensive-drug trials have in fact demonstrated stroke protection with relatively modest $\mathrm{BP}$ reductions. The reduction in average $\mathrm{BP}$ following a reduction in salt intake to 3 or even just to $6 \mathrm{~g} / \mathrm{d}$ may be modest at under $5 \mathrm{mmHg}$, but this is the same level of reduction seen in meta-analyses of antihypertensive-intervention trials (74), which suggests that similar levels of stroke prevention might be achievable. The public health and budgetary implications seem irresistible. Nevertheless, if the highly polarized divide separating those who favor reduction in salt intake from those who oppose it is to be bridged, two complementary approaches are probably necessary: first, much more careful clinical, biochemical, and pharmacologic phenotyping of hypertensive participants in both genetic and in vivo studies; and second, an eventual controlled intervention trial to confirm the effect on outcome.

\section{Acknowledgments}

Kevin M. O'Shaughnessy and Fiona E. Karet wish to acknowledge the support of the British Heart Foundation and the Wellcome Trust, respectively.

Address correspondence to: Fiona E. Karet, Cambridge Institute for Medical Research, Box 139 Addenbrooke's Hospital, Cambridge CB2 2XY, United Kingdom. Phone: 44-1223-762617; Fax: 44-1223-331206; E-mail: fek1000@cam.ac.uk.
1. Taubes, G. 1998. The (political) science of salt. Science. 281:898-907.

2. Taubes, G. 2000. A DASH of data in the salt debate. Science. 288:1319.

3. Veith, I. 1949. Huang Ti Nei Ching Su Wen. The Yellow Emperor's Classic Of Internal Medicine. Williams \& Wilkins. Baltimore, Maryland, USA. 253 pp.

4. Dahl, L.K., and Heine, M. 1975. Primary role of renal homografts in setting chronic blood pressure levels in rats. Circ. Res. 36:692-696.

5. Guyton, A.C. 1991. Abnormal renal function and autoregulation in essential hypertension. Hypertension. 18:49-53.

6. Guyton, A.C. 1991. Blood pressure control: special role of the kidneys and body fluids. Science. 252:1813-1816.

7. Lifton, R.P., Gharavi, A.G., and Geller, D.S. 2001. Molecular mechanisms of human hypertension. Cell. 104:545-556.

8. Liddle, G., Bledsoe, T., and Coppage, W. 1963. A familial renal disorder simulating primary aldosteronism but with negligible aldosterone secretion. Trans. Assoc. Am. Physicians. 76:199-213.

9. Botero-Velez, M., Curtis, J.J., and Warnock, D.G 1994. Brief report. Liddle's syndrome revisited: a disorder of sodium reabsorption in the distal tubule. N. Engl. J. Med. 330:178-181.

10. Shimkets, R.A., et al. 1994. Liddle's syndrome: heritable human hypertension caused by mutations in the beta subunit of the epithelial sodium channel. Cell. 79:407-414.

11. Hansson, J.H., et al. 1995. Hypertension caused by a truncated epithelial sodium channel gamma subunit: genetic heterogeneity of Liddle syndrome. Nat. Genet. 11:76-82.

12. Canessa, C.M., et al. 1994. Amiloride-sensitive epithelial $\mathrm{Na}^{+}$channel is made of three homologous subunits. Nature. 367:463-467.

13. Staub, O., et al. 1996. WW domains of Nedd4 bind to the proline-rich PY motifs in the epithelial $\mathrm{Na}^{+}$ channel deleted in Liddle's syndrome. EMBO J. 15:2371-2380

14. Snyder, P.M., Steines, J.C., and Olson, D.R. 2004. Relative contribution of Nedd4 and Nedd4-2 to $\mathrm{ENaC}$ regulation in epithelia determined by RNA interference. J. Biol. Chem. 279:5042-5046.

15. Naray-Fejes-Toth, A., Canessa, C., Cleaveland, E.S., Aldrich, G., and Fejes-Toth, G. 1999. sgk is an aldosterone-induced kinase in the renal collecting duct. Effects on epithelial $\mathrm{Na}^{+}$channels. J. Biol. Chem. 274:16973-16978.

16. Chen, S.Y., et al. 1999. Epithelial sodium channel regulated by aldosterone-induced protein sgk. Proc. Natl. Acad. Sci. U. S. A. 96:2514-2519.

17. Cheek, D.B., and Perry, J.W. 1958. A salt wasting syndrome in infancy. Arch. Dis. Child. 33:252-256.

18. Chang, S.S., et al. 1996. Mutations in subunits of the epithelial sodium channel cause salt wasting with hyperkalaemic acidosis, pseudohypoaldosteronism type 1 . Nat. Genet. 12:248-253.
19. Strautnieks, S.S., Thompson, R.J., Gardiner, R.M., and Chung, E. 1996. A novel splice-site mutation in the gamma subunit of the epithelial sodium channel gene in three pseudohypoaldosteronism type 1 families. Nat. Genet. 13:248-250.

20. Kerem, E., et al. 1999. Pulmonary epithelial sodium-channel dysfunction and excess airway liquid in pseudohypoaldosteronism. N. Engl. J. Med. 341:156-162.

21. Bartter, F.C., Pronove, P., Gill, J.R., Jr., and MacCardle, R.C. 1962. Hyperplasia of the juxtaglomerular complex with hyperaldosteronism and hypokalemic alkalosis. A new syndrome. Am. J. Med. 33:811-828.

22. Gitelman, H.J., Graham, J.B., and Welt, L.G. 1966. A new familial disorder characterized by hypokalemia and hypomagnesemia. Trans. Assoc. Am. Physicians. 79:221-235.

23. Bettinelli, A., et al. 1992. Use of calcium excretion values to distinguish two forms of primary renal tubular hypokalemic alkalosis: Bartter and Gitelman syndromes. J. Pediatr. 120:38-43.

24. Simon, D.B., et al. 1996. Bartter's syndrome, hypokalaemic alkalosis with hypercalciuria, is caused by mutations in the $\mathrm{Na}-\mathrm{K}-2 \mathrm{Cl}$ cotransporter NKCC2. Nat. Genet. 13:183-188.

25. Simon, D.B., et al. 1996. Genetic heterogeneity of Bartter's syndrome revealed by mutations in the $\mathrm{K}^{+}$ channel, ROMK. Nat. Genet. 14:152-156.

26. Simon, D.B., et al. 1997. Mutations in the chloride channel gene, $C L C N K B$, cause Bartter's syndrome type III. Nat. Genet. 17:171-178.

27. Estevez, R., et al. 2001. Barttin is a $\mathrm{Cl}$ channel betasubunit crucial for renal $\mathrm{Cl}$ reabsorption and inner ear $\mathrm{K}^{+}$secretion. Nature. 414:558-561.

28. Birkenhager, R., et al. 2001. Mutation of BSND causes Bartter syndrome with sensorineural deafness and kidney failure. Nat. Genet. 29:310-314.

29. Cruz, D.N., Shaer, A.J., Bia, M.J., Lifton, R.P., and Simon, D.B. 2001. Gitelman's syndrome revisited an evaluation of symptoms and health-related quality of life. Kidney Int. 59:710-717.

30. Simon, D.B., et al. 1996. Gitelman's variant of Bartter's syndrome, inherited hypokalaemic alkalosis, is caused by mutations in the thiazide-sensitive $\mathrm{Na}-\mathrm{Cl}$ cotransporter. Nat. Genet. 12:24-30.

31. Gordon, R.D., Geddes, R.A., Pawsey, C.G., and O'Halloran, M.W. 1970. Hypertension and severe hyperkalaemia associated with suppression of renin and aldosterone and completely reversed by dietary sodium restriction. Australas. Ann. Med. 19:287-294.

32. Mansfield, T.A., et al. 1997. Multilocus linkage of familial hyperkalaemia and hypertension, pseudohypoaldosteronism type II, to chromosomes $1 \mathrm{q} 31-42$ and 17p11-q21. Nat. Genet. 16:202-205.

33. Disse-Nicodeme, S., et al. 2000. A new locus on chromosome 12p13.3 for pseudohypoaldosteronism type II, an autosomal dominant form of hypertension. Am. J. Hum. Genet. 67:302-310.

34. Wilson, F.H., et al. 2001. Human hypertension caused by mutations in WNK kinases. Science. 293:1107-1112.

35. Choate, K.A., Kahle, K.T., Wilson, F.H., NelsonWilliams, C., and Lifton, R.P. 2003. WNK1, a kinase mutated in inherited hypertension with hyperkalemia, localizes to diverse $\mathrm{Cl}$-transporting epithelia. Proc. Natl. Acad. Sci. U. S. A. 100:663-668.

36. Yang, C.-L., Angell, J., Mitchell, R., and Ellison, D.H. 2003. WNK kinases regulate thiazide-sensitive $\mathrm{Na}-\mathrm{Cl}$ cotransport. J. Clin. Invest. 111:1039-1045. doi:10.1172/JCI200317443.

37. Wilson, F.H., et al. 2003. Molecular pathogenesis of inherited hypertension with hyperkalemia: the $\mathrm{Na}-\mathrm{Cl}$ cotransporter is inhibited by wild-type but not mutant WNK4. Proc. Natl. Acad. Sci. U. S. A. 100:680-684.

38. Kahle, K.T., et al. 2003. WNK4 regulates the balance between renal $\mathrm{NaCl}$ reabsorption and $\mathrm{K}^{+}$secretion. Nat. Genet. 35:372-376.

39. Jeunemaitre, X. 2003. Renin-angiotensin-aldosterone system polymorphisms and essential hypertension: where are we? J. Hypertens. 21:2219-2222.

40. Harrap, S.B. 2003. Where are all the blood-pressure genes? Lancet. 361:2149-2151.

41. Corvol, P., Persu, A., Gimenez-Roqueplo, A.P., and Jeunemaitre, X. 1999. Seven lessons from two candidate genes in human essential hypertension: angiotensinogen and epithelial sodium channel. Hypertension. 33:1324-1331.

42. Province, M.A., et al. 2003. A meta-analysis of genome-wide linkage scans for hypertension: the National Heart, Lung and Blood Institute Family Blood Pressure Program. Am. J. Hypertens. 16:144-147.

43. Kim, H.S., et al. 1995. Genetic control of blood pressure and the angiotensinogen locus. Proc. Natl. Acad. Sci. U. S. A. 92:2735-2739.

44. Kim, H.S., et al. 1999. Homeostasis in mice with genetically decreased angiotensinogen is primarily by an increased number of renin-producing cells. J. Biol. Chem. 274:14210-14217.

45. Pradervand, S., et al. 2003. Dysfunction of the epithelial sodium channel expressed in the kidney of a mouse model for Liddle syndrome. J. Am. Soc. Nephrol. 14:2219-2228.

46. Dahlmann, A., et al. 2003. Mineralocorticoid regulation of epithelial $\mathrm{Na}^{+}$channels is maintained in a mouse model of Liddle's syndrome. Am. J. Physiol. Renal Physiol. 285:F310-F318.

47. Dahl, L.K., Heine, M., and Tassinari, L. 1962. Effects of chronic excess salt ingestion: evidence that genetic factors play an important role in susceptibility to experimental hypertension. J. Exp. Med. 115:1173-1190.

48. Denton, D., et al. 1995. The effect of increased salt intake on blood pressure of chimpanzees. Nat. Med. 1:1009-1016.

49. Dahl, L.K. 1960. Possible role of salt intake in the development of essential hypertension. In Essential bypertension: an international symposium. P. Cottier 
and K.D. Bock, editors. Springer-Verlag. Berlin, Germany. 61-75.

50. 1988. Intersalt: an international study of electrolyte excretion and blood pressure. Results for 24 hour urinary sodium and potassium excretion. Intersalt Cooperative Research Group. Br. Med. J. 297:319-328.

51. Elliott, P., et al. 1996. Intersalt revisited: further analyses of 24 hour sodium excretion and blood pressure within and across populations. Intersalt Cooperative Research Group. Br. Med. J. 312:1249-1253.

52. Law, M.R., Frost, C.D., and Wald, N.J. 1991. By how much does dietary salt reduction lower blood pressure? III. Analysis of data from trials of salt reduction. Br. Med. J. 302:819-824.

53. He, F.J., and MacGregor, G.A. 2003. How far should salt intake be reduced? Hypertension. 42:1093-1099.

54. Sacks, F.M., et al. 2001. Effects on blood pressure of reduced dietary sodium and the dietary approaches to stop hypertension (DASH) diet. N. Engl.J. Med. 344:3-10.

55. Neri, L.C., and Johansen, H.L. 1978. Water hardness and cardiovascular mortality. Ann. N. Y. Acad. Sci. 304:203-221.

56. Lind, L., Lithell, H., Gustafsson, I.B., Pollare, T., and Ljunghall, S. 1993. Calcium metabolism and sodium sensitivity in hypertensive subjects. J. Hum. Hypertens. 7:53-57.

57. Cappuccio, F.P., and MacGregor, G.A. 1991. Does potassium supplementation lower blood pressure? A meta-analysis of published trials. J. Hypertens. 9:465-473.
58. Ascherio, A., et al. 1998. Intake of potassium, magnesium, calcium, and fiber and risk of stroke among US men. Circulation. 98:1198-1204.

59. Verhaar, M.C., Stroes, E., and Rabelink, T.J. 2002 Folates and cardiovascular disease. Arterioscler. Thromb. Vasc. Biol. 22:6-13.

60. Rathaus, M., and Bernheim, J. 2002. Oxygen species in the microvascular environment: regulation of vascular tone and the development of hypertension. Nephrol. Dial. Transplant. 17:216-221.

61. 2004. Dietary reference intakes: water, potassium, sodium, chloride, and sulfate. Report of the Institute of Medicine of the National Academies. Washington, DC, USA. http://www.iom.edu/report.asp?id=18495.

62. Luft, F.C., and Weinberger, M.H. 1997. Heterogeneous responses to changes in dietary salt intake: the salt-sensitivity paradigm. Am. J. Clin. Nutr. 65(Suppl. 2):612S-617S.

63. Luft, F.C., et al. 1987. Influence of genetic variance on sodium sensitivity of blood pressure. Klin. Wochenschr. 65:101-109.

64. Svetkey, L.P., et al. 2001. Angiotensinogen genotype and blood pressure response in the Dietary Approaches to Stop Hypertension (DASH) study. J. Hypertens. 19:1949-1956.

65. Weir, M.R., et al. 1998. Influence of race and dietary salt on the antihypertensive efficacy of an angiotensin-converting enzyme inhibitor or a calcium channel antagonist in salt-sensitive hypertensives. Hypertension. 31:1088-1096.

66. Berghoff, R.S., and Geraci, A.S. 1929. The influence of sodium chloride on blood pressure. Br. Med. J. 56:395-397.
67. Shore, A.C., Markandu, N.D., and MacGregor, G.A. 1988. A randomized crossover study to compare the blood pressure response to sodium loading with and without chloride in patients with essential hypertension. J. Hypertens. 6:613-617.

68. Kurtz, T.W., Al Bander, H.A., and Morris, R.C., Jr. 1987. "Salt-sensitive" essential hypertension in men. Is the sodium ion alone important? N. Engl.J. Med. 317:1043-1048.

69. Dodic, M., Moritz, K., Koukoulas, I., and Wintour, E.M. 2002. Programmed hypertension: kidney, brain or both? Trends Endocrinol. Metab. 13:403-408.

70. Zicha, J., and Kunes, J. 1999. Ontogenetic aspects of hypertension development: analysis in the rat. Physiol. Rev. 79:1227-1282.

71. Holliday, M.A. 1995. Is blood pressure in later life affected by events in infancy? Pediatr. Nephrol. 9:663-666.

72. Antihypertensive and Lipid-Lowering Treatment to Prevent Heart Attack Trial Collaborative Research Group. 2003. Diuretic versus alpha-blocker as firststep antihypertensive therapy: final results from the Antihypertensive and Lipid-Lowering Treatment to Prevent Heart Attack Trial (ALLHAT). Hypertension. 42:239-246.

73. Luft, F.C., Morris, C.D., and Weinberger, M.H. 1997. Compliance to a low-salt diet. Am. J. Clin. Nutr. 65(Suppl. 2):698S-703S

74. Collins, R., et al. 1990. Blood pressure, stroke, and coronary heart disease. Part 2. Short-term reductions in blood pressure: overview of randomised drug trials in their epidemiological context. Lancet. 335:827-838. 